JPBJ, Vol. 7 No. 1, Februari 2021

ISSN: 2613-9618

\title{
PENERAPAN FLIPPED CLASSROOM PADA PEMBELAJARAN DARING BAHASA JEPANG DI KELAS XII SMK SARASWATI 3 DENPASAR
}

\author{
N.L.G. Meilantari ${ }^{1}$ \\ ${ }^{123}$ Program Studi Sastra Jepang, Universitas Mahasaraswati, Denpasar \\ e-mail: meilantari@unmas.ac.id
}

\begin{abstract}
ABSTRAK
Bahasa Jepang merupakan bahasa asing yang muncul di dalam kurikulum pendidikan di kelas XII SMK Saraswati 3 Denpasar. Sebagai mata pelajaran bahasa, pelajaran Bahasa Jepang menekankan pada empat keterampilan berbahasa, yaitu membaca, menulis, berbicara dan mendengar. Tetapi karena hanya muncul di kelas XII, maka pembelajaran bahasa Jepang di SMK Saraswati 3 Denpasar, ditekankan pada kemampuan komunikasi. Komunikasi yang dimaksud adalah mampu berbicara dengan bahasa Jepang sederhana (level A1).

Salah satu metode yang digunakan dalam pembelajaran bahasa Jepang di SMK Saraswati 3 Denpasar adalah melalui model flipped classroom. Model flipped classroom adalah model pembelajaran yang menggabungkan ide tradisional tentang pengajaran dan aktivitas di dalam kelas. Dalam model ini, siswa diberikan tugas untuk menonton video pengajaran yang diberikan guru di rumah, kemudian didiskusikan dan dipraktekan ketika berada di kelas. Model pembelajaran ini dipilih karena selama pandemi Covid-19 merebak sejak awal tahun 2020, pembelajaran dilakukan melalui daring (dalam jaringan) yaitu menggunakan google classroom. Penulis melihat kejenuhan siswa dalam belajar daring dan berinisiatif untuk melakukan pembelajaran melalui model flipped classroom. Penulis percaya, dengan mempercayakan siswa mencari sendiri dan mempersiapkan diri di rumah, diharapkan di kelas, siswa lebih aktif berdiskusi dan berkomunikasi dengan teman sejawatnya maupun dengan guru sehingga capaian pembelajaran bisa lebih cepat tercapai.
\end{abstract}

Kata kunci : flipped classroom, pembelajaran bahasa 
JPBJ, Vol. 7 No. 1, Februari 2021

ISSN: 2613-9618

\section{Pendahuluan}

Berdasarkan jajak pendapat dari The Japan Foundation tahun 2018, Indonesia adalah negara pembelajar bahasa Jepang kedua di dunia, setelah China. Ini dibuktikan dengan banyaknya lembaga kursus dan pendidikan bahasa Jepang berada di Indonesia. Melihat kenyataan itu, tentu tidak mengherankan jika bahasa Jepang masuk ke dalam kurikulum pendidikan menengah di Indonesia. Hal ini bisa dilihat melalui tabel berikut.

\section{Tabel 1.1 Jumlah Pembelajar Bahasa Jepang di Seluruh Dunia}

\begin{tabular}{|c|c|c|c|c|c|c|c|c|c|c|c|}
\hline \multirow[b]{2}{*}{ 順位 } & \multirow[b]{2}{*}{$\begin{array}{c}2015 \text { 年 } \\
\text { 順位 }\end{array}$} & \multirow[b]{2}{*}{ 国·地域 } & \multicolumn{3}{|c|}{ 学習者 (人) } & \multicolumn{3}{|c|}{ 機関 (機関) } & \multicolumn{3}{|c|}{ 教師 (人) } \\
\hline & & & 2018年 & 2015 年 & $\begin{array}{c}\text { 増減率 } \\
(\%)\end{array}$ & 2018年 & 2015年 & $\begin{array}{c}\text { 増減率 } \\
\text { (\%) }\end{array}$ & 2018年 & 2015年 & $\begin{array}{l}\text { 増滅率 } \\
(\%)\end{array}$ \\
\hline 1 & 1 & 中国 & $1,004,625$ & 953,283 & 5.4 & 2,435 & 2,115 & 15.1 & 20,220 & 18,312 & 10.4 \\
\hline 2 & 2 & インドネシア & 709,479 & 745,125 & $\Delta 4.8$ & 2,879 & 2,496 & 15.3 & 5,793 & 4,540 & 27.6 \\
\hline 3 & 3 & 韓国 & 531,511 & 556,237 & $\bar{\Delta}_{4.4}$ & 2,998 & 2,862 & 4.8 & 15,345 & 14,855 & 3.3 \\
\hline 4 & 4 & オーストラリア & 405,175 & 357,348 & 13.4 & 1,764 & 1,643 & 7.4 & 3,135 & 2,800 & 12.0 \\
\hline 5 & 6 & タイ & 184,962 & 173,817 & 6.4 & 659 & 606 & 8.7 & 2,047 & 1,911 & 7.1 \\
\hline 6 & 8 & ベトナム & 174,521 & 64,863 & 169.1 & 818 & 219 & 273.5 & 7,030 & 1,795 & 291.6 \\
\hline 7 & 5 & 台湾 & 170,159 & 220,045 & $\boldsymbol{\Delta} 22.7$ & 846 & 851 & $\mathbf{\Delta} 0.6$ & 4,106 & 3,877 & 5.9 \\
\hline 8 & 7 & 米国 & 166,905 & 170,998 & $\mathbf{\Delta} 2.4$ & 1,446 & 1,462 & $\Delta 1.1$ & 4,021 & 3,894 & 3.3 \\
\hline 9 & 9 & フィリピン & 51,530 & 50,038 & 3.0 & 315 & 209 & 50.7 & 1,289 & 721 & 78.8 \\
\hline 10 & 10 & マレーシア & 39,247 & 33,224 & 18.1 & 212 & 176 & 20.5 & 485 & 430 & 12.8 \\
\hline 11 & 12 & インド & 38,100 & 24,011 & 58.7 & 304 & 184 & 65.2 & 1,006 & 655 & 53.6 \\
\hline 12 & 19 & ミャンマー & 35,600 & 11,301 & 215.0 & 411 & 132 & 211.4 & 1,593 & 524 & 204.0 \\
\hline 13 & 11 & ニュージーランド & 32,764 & 29,925 & 9.5 & 275 & 257 & 7.0 & 421 & 378 & 11.4 \\
\hline 14 & 13 & ブラジル & 26,157 & 22,993 & 13.8 & 380 & 352 & 8.0 & 1,182 & 1,140 & 3.7 \\
\hline 15 & 14 & 香港 & 24,558 & 22,613 & 8.6 & 70 & 70 & 0.0 & 575 & 523 & 9.9 \\
\hline 16 & 15 & フランス & 24,150 & 20,875 & 15.7 & 229 & 222 & 3.2 & 763 & 723 & 5.5 \\
\hline 17 & 16 & 英国 & 20,040 & 20,093 & $\boldsymbol{\Delta} 0.3$ & 288 & 364 & $\boldsymbol{\Delta} 20.9$ & 646 & 704 & $\boldsymbol{\Delta} 8.2$ \\
\hline 18 & 17 & カナダ & 19,489 & 19,601 & $\boldsymbol{\Delta} 0.6$ & 161 & 178 & $\boldsymbol{\Delta} 9.6$ & 662 & 727 & $\boldsymbol{\Delta} 8.9$ \\
\hline 19 & 18 & ドイツ & 15,465 & 13,256 & 16.7 & 157 & 181 & $\boldsymbol{\Delta} 13.3$ & 473 & 457 & 3.5 \\
\hline 20 & 23 & メキシコ & 13,673 & 9,240 & 48.0 & 120 & 68 & 76.5 & 483 & 322 & 50.0 \\
\hline 21 & 20 & シンガポール & 12,300 & 10,798 & 13.9 & 19 & 30 & $\mathbf{\Delta} 36.7$ & 221 & 227 & $\boldsymbol{\Delta} 2.6$ \\
\hline 22 & 24 & ロシア & 11,764 & 8,650 & 36.0 & 169 & 126 & 34.1 & 633 & 480 & 31.9 \\
\hline 23 & 22 & モンゴル & 11,755 & 9,914 & 18.6 & 128 & 76 & 68.4 & 363 & 253 & 43.5 \\
\hline 24 & 26 & スペイン & 8,495 & 5,122 & 65.9 & 141 & 80 & 76.3 & 325 & 192 & 69.3 \\
\hline 25 & 21 & スリランカ & 8,454 & 10,120 & $\Delta 16.5$ & 77 & 76 & 1.3 & 125 & 132 & $\boldsymbol{\Delta} 5.3$ \\
\hline 26 & 25 & イタリア & 7,831 & 7,031 & 11.4 & 62 & 51 & 21.6 & 235 & 193 & 21.8 \\
\hline 27 & 30 & カンボジア & 5,419 & 4,009 & 35.2 & 51 & 29 & 75.9 & 307 & 157 & 95.5 \\
\hline 28 & 28 & ネパール & 5,326 & 4,262 & 25.0 & 126 & 106 & 18.9 & 443 & 376 & 17.8 \\
\hline 29 & 33 & アルゼンチン & 5,054 & 3,571 & 41.5 & 46 & 42 & 9.5 & 206 & 192 & 7.3 \\
\hline 30 & 38 & バングラデシュ & 4,801 & 2,158 & 122.5 & 85 & 37 & 129.7 & 220 & 94 & 134.0 \\
\hline 31 & 27 & ポーランド & 4,483 & 4,416 & 1.5 & 48 & 57 & $\boldsymbol{\Delta} 15.8$ & 200 & 222 & $\boldsymbol{\Delta} 9.9$ \\
\hline 32 & 29 & ペルー & 3,792 & 4,074 & $\boldsymbol{\Delta} 6.9$ & 10 & 19 & $\mathbf{\Delta} 47.4$ & 72 & 92 & $\Delta 21.7$ \\
\hline 33 & 35 & コートジボワール & 3,392 & 2,662 & 27.4 & 11 & 7 & 57.1 & 16 & 15 & 6.7 \\
\hline 34 & 120 & トルクメニスタン & 3,259 & 49 & 6551.0 & 9 & 1 & 800.0 & 35 & 5 & 600.0 \\
\hline 35 & 31 & パラグアイ & 3,010 & 3,725 & $\boldsymbol{\Delta} 19.2$ & 12 & 16 & $\boldsymbol{\Delta} 25.0$ & 146 & 91 & 60.4 \\
\hline
\end{tabular}

(Sumber: https://www.jpf.go.jp/i/project/japanese/survey/result/dl/survey2018/all.pdf)

Bahasa Jepang, dalam struktur kurikulum SMK 2013 yang diperbaharui tahun 2018 berdasarkan Peraturan Direktur Jenderal Pendidikan Dasar Menengah No. 7/D.D5/KK/2018 tanggal 2018 termasuk ke dalam mata pelajaran muatan nasional sebagai bahasa asing lainnya. SMK Saraswati 3 memilih Bahasa Jepang karena selain berlokasi di Denpasar, Bali, yang merupakan daerah pariwisata, pemilihan bahasa Jepang juga disebabkan oleh beberapa kerjasama yang dilakukan oleh Yayasan Perguruan Rakyat Saraswati dengan pihak dari Jepang.

Sebagai bahasa asing, pembelajaran bahasa Jepang hampir sama dengan pembelajaran bahasa asing lainnya. Tetapi untuk di SMK Saraswati 3, pembelajaran bahasa Jepang lebih ditekankan pada kemampuan verbal/komunikasi siswa. Penekanan pada kemampuan verbal/komunikasi siswa dianggap tepat karena dapat diterapkan langsung oleh siswa pada saat mereka akan bekerja atau melaksanakan praktik kerja. 
JPBJ, Vol. 7 No. 1, Februari 2021

ISSN: 2613-9618

Menurut Wicaksono (2016:1), teori dalam pembelajaran bahasa, pada umumnya didasarkan pada empat konsep kunci: bahasa, belajar, mengajar bahasa dan konteks. 1) Pembelajaran bahasa membutuhkan suatu konsep tentang hakikat bahasa. 2) Pembelajaran bahasa membutuhkan pandangan dan wawasan tentang pelajar dan hakikat belajar bahasa. 3) Pembelajaran bahasa mengimplikasikan pandangan tentang pengajar bahasa. Pembelajaran bahasa terjadi pada konteks tertentu. Penafsiran konteks amat penting dalam teori ini. Dengan penafsiran konteks, dan lebih menekankan pada kemampuan verbal/komunikasi, metode flipped classroom sangat bermanfaat dalam pengajaran bahasa Jepang di SMK Saraswati 3 Denpasar.

Terlebih saat pandemi Covid-19, pembelajaran dilakukan secara daring (dalam jaringan). Pembelajaran daring membutuhkan kreativitas dalam mengajar agar siswa merasa tidak bosan dan tetap bersemangat dalam mengikuti pelajaran. Salah satu metode pengajaran yang digunakan dalam pembelajaran daring pelajaran bahasa Jepang di SMK Sasraswati 3 Denpasar adalah flipped classroom.

Flipped classroom pertama kali diperkenalkan sekitar tahun 2008 oleh guru veteran dari Woodland Park High School, Colorado, bernama Jonathan Bergmann dan Aaron Adams. Mereka merasa ingin membantu para siswa yang kesulitan dalam memahami pelajaran ataupun siswa yang tidak sempat hadir di kelas karena sakit atau dispensasi mengikuti kegiatan di luar sekolah. Menurut Bergmann (2012:13-15), pada dasarnya konsep dari flipped classroom adalah "membalikkan" konsep pembelajaran tradisional. Apa yang dalam pembelajaran tradisional dilakukan di kelas, di lakukan di rumah dan pekerjaan rumah, yang biasanya dikerjakan di rumah, dikerjakan di sekolah pada saat pelajaran berlangsung.

Metode flipped classroom yang dilakukan Bergmann biasanya membuat guru menyertakan video pembelajaran interaktif yang harus dipelajari oleh siswa di rumah sebelum pelajaran di kelas dimulai. Dengan video pembelajaran interaktif dari guru, hal-hal dan instruksi dari guru yang biasa terjadi di kelas, bisa diakses di rumah. Kelas menjadi tempat untuk memecahkan masalah yang dialami atau berdiskusi tentang pertanyaan dari materi dan guru serta siswa bisa terlibat dalam pembelajaran kolabolari atau collaborative learning (Tucker, 2012:83).

Bergmann sendiri (dalam Tucker 2012: 83) mengakui bahwa dalam flipped classroom, siswa tidak cukup hanya dengan dengan menonton video pembelajaran dari dosen lalu selesai. Siswa diharuskan membuat pertanyaan terkait materi dalam video dan mengemukakan di kelas. Guru juga harus memeriksa catatan dari siswa. Dengan begini, guru bisa memberi perbedaan dibanding kelas yang dilakukan secara konvensional.

Meski begitu, karena berkembang menjadi trend baru, penerapan flipped classroom kebanyakan ditulis dalam blog, majalah online dan bukan pada paper penelitian atau seminar ilmiah, sehingga agak sulit mengukur efektivitasnya. Penelitian yang dilakukan Atteberry (2013) di Harvey Mudd College menyebutkan bahwa flipped clasroom tidak terlalu banyak mengubah penerimaan siswa terhadap pembelajaran di kelas. Sedangkan penelitian yang dilakukan Mok terhadap 46 siswa dari kelas sistem informasi semester 2013 menyebutkan bahwa siswa yang terlibat merasa puas dan ini merupakan metode pembelajaran yang efektif (Mok, 2014:9).

Artikel ini akan melanjutkan penelitian terdahulu tentang bagaimanakah penerapan flipped classroom pada pembelajaran daring pelajaran Bahasa Jepang di SMK Saraswati 3 Denpasar? Serta bagaimana tanggapan siswa terhadap pelaksanaan pembelajaran daring melalui flipped classroom? Pembelajaran bahasa Jepang terkait dengan konteks, maka dirasa metode ini cukup efektif diterapkan pada masa pandemi Covid-19 seperti sekarang. 
JPBJ, Vol. 7 No. 1, Februari 2021

ISSN: 2613-9618

\section{Metode Penelitian}

Penelitian ini adalah penelitian kualitatif dengan fokus penelitian pada penerapan flipped classroom pada pembelajaran daring Bahasa Jepang dan tanggapan siswa terhadap pelaksanaan pembelajaran. Sample dari penelitian adalah siswa kelas XII SMK Saraswati 3 Denpasar yang berjumlah 80 orang dan mengikuti pelajaran Bahasa Jepang selama semester ganjil 2019/2020 atau sekitar bulan Juli-Desember 2020.

Teknik pengambilan data melalui teknik triangulasi. Sugiyono (2016: 241) menjelaskan bahwa triangulasi teknik berarti peneliti menggunakan teknik pengumpulan data berbeda untuk mendapatkan data dari sumber yang sama. Sehingga dalam penelitian ini digunakan teknik observasi partisipatif, dokumentasi dan wawancara. Sehubungan pandemi, semua proses pengambilan data dilakukan secara online, melalui fasilitas google meet, google form dan google classroom.

Metode analisis data di lapangan menggunakan model Miles dan Huberman. Miles dan Hubberman (dalam Sugiyono, 2016: 246-247) menyatakan bahwa aktivitas pada analisis data kualitatif dilakukan secara interaktif dan terus menerus. Aktivitas analisis data model Miles dan Huberman terdiri dari pengumpulan data, reduksi data, penyajian data dan simpulan.

\section{Hasil dan Pembahasan}

Pelajaran Bahasa Jepang di SMK Saraswati 3 berlangsung sekali seminggu selama $2 \times 45$ menit (2 jam pelajaran). Sebelum pandemi, pada kelas konvensional, pembelajaran bahasa Jepang di SMK Saraswati 3 Denpasar lebih ke arah teacher centered learning. Guru menjelaskan hal-hal yang ada di buku teks, yaitu Marugoto A1 Activities yang disusun oleh The Japan Foundation dan di Indonesia sendiri, diterbitkan oleh Kesaint Blanc. Biasanya guru menghabiskan waktu sekitar 20 menit untuk warming up, bertanya dalam bahasa Jepang sederhana tentang PR ataupun topik pelajaran minggu lalu sebelum melanjutkan ke topik minggu ini. Kemudian menjelaskan tema pelajaran sekitar 45 hingga 50 menit. Sisa waktu yang tersisa digunakan untuk latihan dan review, baik latihan percakapan maupun kuis/tes kecil. Untuk lebih memantapkan pemahaman siswa tentang materi pembelajaran, seperti biasa, guru melakukan penugasan kepada siswa.

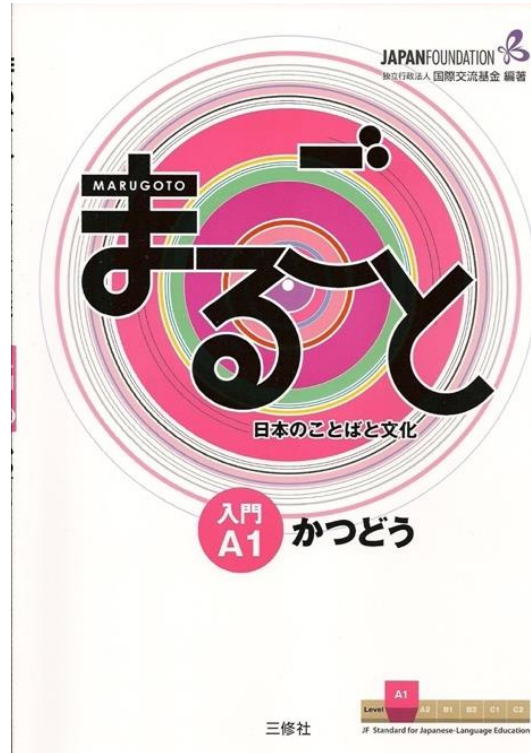

Gambar 1. Sampul buku teks Marugoto

(Sumber: dokumen pribadi) 
Sedangkan pada penerapan flipped classroom, sebelum semester baru dimulai, siswa dibagikan kode google classroom di grup Whatsapp kelas. Materi berupa buku elektronik Marugoto A1, slide powerpoint dan video pembelajaran diunggah di google classroom 3 hari sebelum kelas dimulai. Bukan hanya materi, guru juga memotivasi siswa agar membuat beberapa pertanyaan yang terkait materi untuk didiskusikan saat pertemuan di kelas menggunakan google meet. Di hari pelajaran bahasa Jepang, pada sesi warming up, guru langsung menjawab beberapa pertanyaan dari siswa terkait materi yang sudah diunggah. Sisa waktu selanjutnya digunakan untuk latihan dan memperdalam pengetahuan tentang materi yang dibahas. Jika ditulis dalam bentuk tabel, berikut adalah perbandingan alokasi waktu pada kelas konvensional dan flipped classroom.

\begin{tabular}{|c|c|c|c|}
\hline \multicolumn{2}{|c|}{ Kelas konvensional } & \multicolumn{2}{|c|}{ Flipped classroom } \\
\hline Aktivitas & Alokasi waktu & Aktivitas & Alokasi waktu \\
\hline Warming up & 5 menit & Warming up & 5 menit \\
\hline $\begin{array}{l}\text { Review pelajaran } \\
\text { lalu/pembahasan } \\
\text { PR }\end{array}$ & 15 menit & $\begin{array}{l}\text { Pembahasan } \\
\text { video/materi yang } \\
\text { sudah diunggah }\end{array}$ & 25 menit \\
\hline $\begin{array}{l}\text { Penjelasan } \\
\text { materi hari itu }\end{array}$ & 45 menit & Latihan/praktik & 60 menit \\
\hline Latihan/praktik & 25 menit & Jikohyouka & - \\
\hline
\end{tabular}

Tabel 1. Perbandingan alokasi waktu kelas konvensional dan flipped classroom

Dari tabel di atas bisa dilihat jika kelas konvensional lebih terpusat pada guru. Waktu pelajaran lebih banyak dihabiskan untuk menjelaskan materi. Sedangkan pada flipped classroom, guru hanya sebagai fasilitator. Karena alokasi waktu lebih banyak digunakan untuk berdiskusi dan latihan. Semua berpusat pada siswa yang lebih aktif bertanya. Selain itu, flipped classroom memungkinkan siswa untuk membuat jikohyouka atau penilaian kemampuan sendiri yang juga diunggah siswa di google classroom tetapi hanya bisa dilihat oleh siswa dan guru.

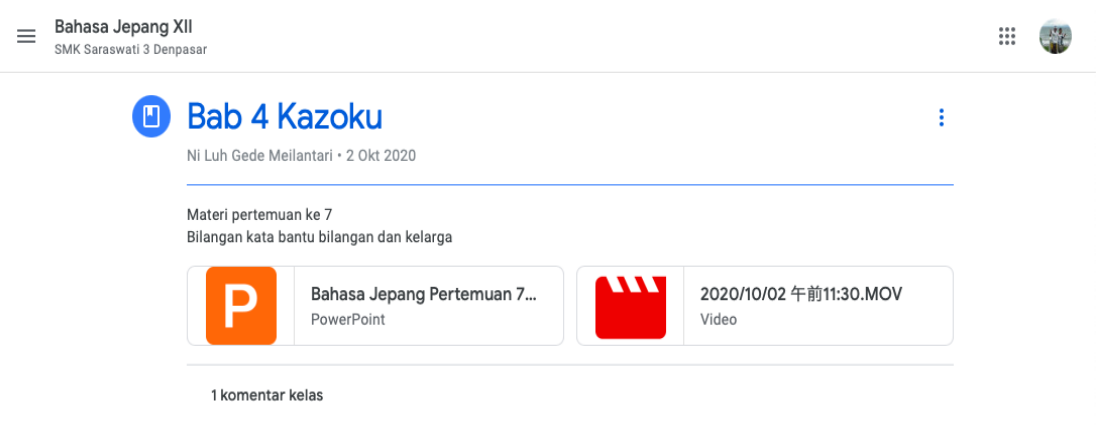

Gambar 2. Contoh materi yang diunggah di Google Classroom (sumber: dokumen pribadi) 
JPBJ, Vol. 7 No. 1, Februari 2021

ISSN: 2613-9618

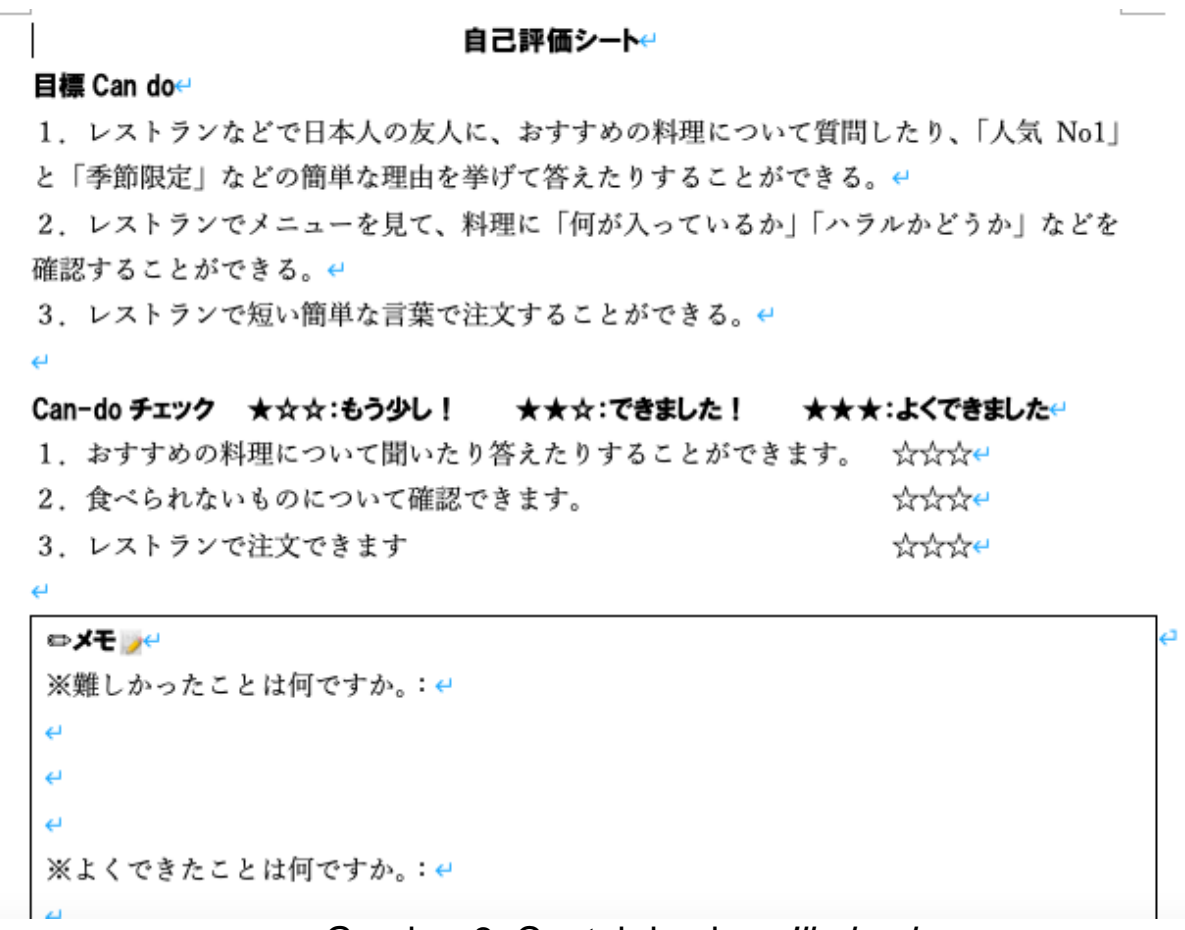

Gambar 3. Contoh lembar Jikohyoka

(sumber: dokumen pribadi)

Di awal-awal pertemuan dan penerapan flipped classroom, siswa belum sepenuhnya sadar bahwa harus menonton video dan membaca terlebih dahulu materi yang sudah diunggah sebelum pelajaran. Hanya beberapa siswa yang menonton dan membaca materi. Siswa juga tidak terbiasa untuk bertanya, sehingga guru akhirnya mewajibkan agar siswa bertanya tentang materi di hari pelajaran berlangsung. Terkadang, diskusi bukan hanya melalui google meet tetapi juga kolom komentar di google classroom.

Seperti pada saat materi pelajaran Bab 3 tentang kosakata yang digunakan di dalam kelas. Siswa menjawab pertanyaan dari guru (Sensei) dalam bahasa Jepang sesuai dengan materi yang sudah dibagikan sebelumnya. Siswa sangat tanggap dalam menanggapi pertanyaan guru tentang keberadaan teman sekelas mereka. Saat guru bertanya, "Farida san imasuka? (Farida ada?)" Siswa mampu merespon dengan baik pertanyaan tersebut dengan menjawab, "lie, mada desu Sensei. (Tidak, belum Sensei)". 
JPBJ, Vol. 7 No. 1, Februari 2021

ISSN: 2613-9618

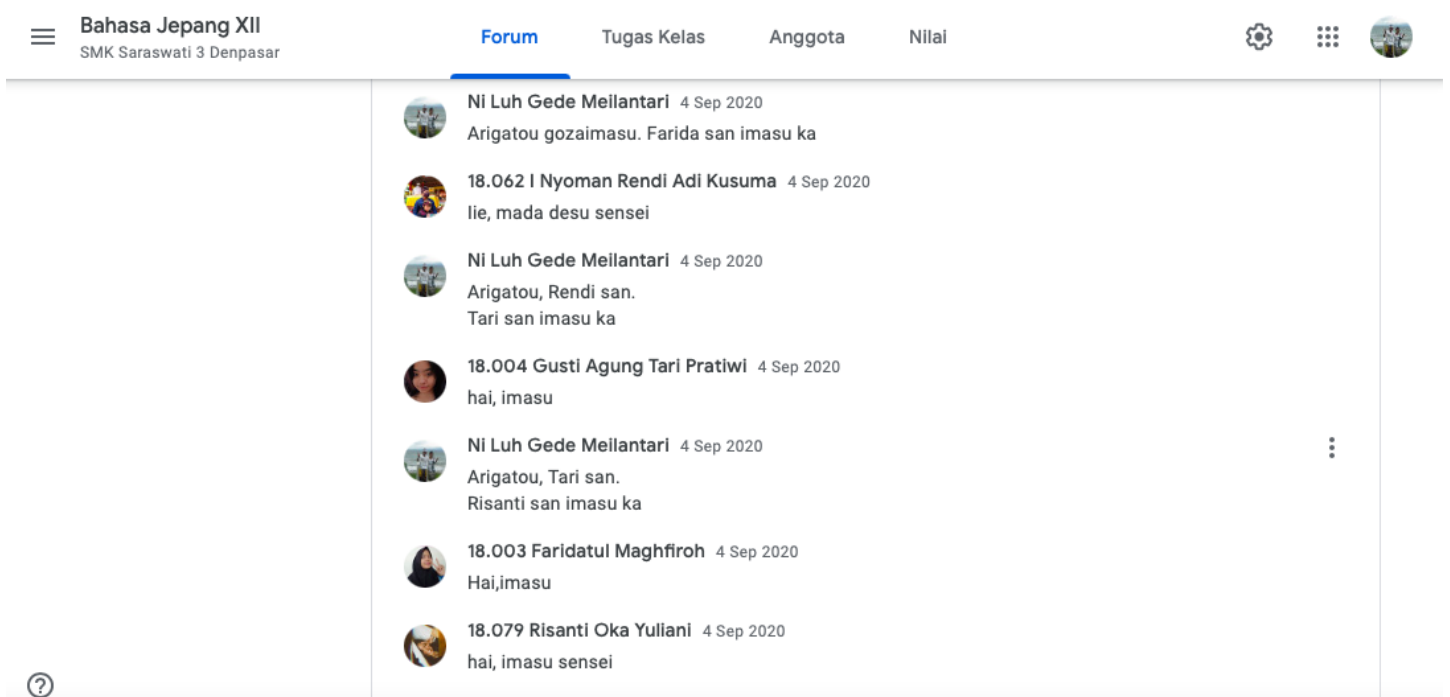

Gambar 3. Contoh jawaban siswa terhadap pertanyaan guru

(Sumber: dokumen pribadi)

Alokasi waktu untuk latihan dan eksplorasi pada flipped classroom cukup banyak dibandingkan kelas konvensional. Pembelajaran daring juga memudahkan siswa untuk merekam terutama pada saat mereka melakukan latihan percakapan. Sehingga nantinya bisa ditonton bersama dan terkadang dikoreksi bersama terutama pada hatsuon (pelafalan). Di akhir pelajaran, siswa juga didorong untuk menyimpulkan apa yang mereka peroleh dari pelajaran hari itu dan tidak lupa untuk memberikan penilaian terhadap diri mereka sendiri (jikohyouka).

Sama seperti model flipped classroom lainnya, penerapan flipped classroom pada pembelajaran daring mata pelajaran Bahasa Jepang di SMK Saraswati 3 Denpasar hanya berbeda pada proses pembelajaran di dalam kelas. Proses penilaian maupun tes dan ulangan harian hampir tidak jauh berbeda dengan kelas konvensional. Bedanya adalah, dengan menerapkan flipped classroom, siswa dapat lebih mengeksplorasi kemampuannya. Hasil evaluasi yang dilakukan di tengah dan akhir semester menunjukan bahwa pada evaluasi tengah semester, nilai rerata siswa sangat kecil. Pada evaluasi di akhir semester, nilai bahasa Jepang siswa mengalami peningkatan. Seperti bisa terlihat dalam gambar di bawah.

\section{Wawasan}

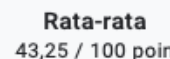

$43,25 / 100$ poin

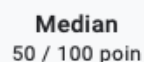

$50 / 100$ poin

Distribusi poin total

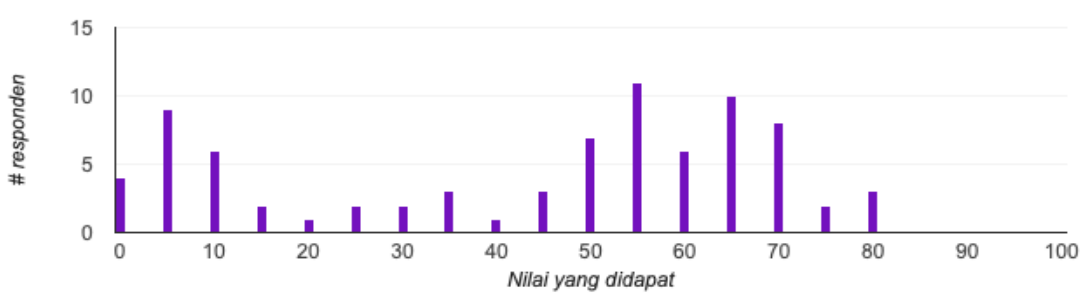

Gambar 4. Hasil evaluasi tengah semester

(Sumber: dokumen pribadi) 
Dari gambar di atas bisa terlihat jika rerata siswa memperoleh nilai di bawah KKM, dengan nilai 50 dari total 80 poin. Kurang dari 5 orang siswa yang memperoleh nilai tertinggi, yaitu 80 . Bahkan ada beberapa siswa yang mendapatkan nilai 0 . Sedangkan nilai evaluasi di akhir semester bisa dilihat pada gambar berikut.

\section{四 Wawasan}

Rata-rata

$90,19 / 100$ poin
Median

$90 / 100$ poin
Rentang

70 - 95 poin

Distribusi poin total

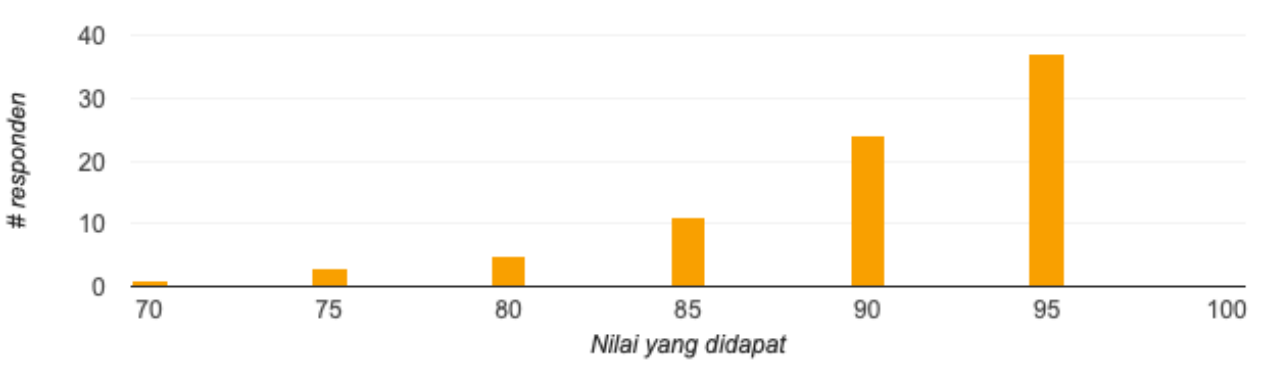

Gambar 5. Hasil evaluasi akhir semester (Sumber: dokumen pribadi)

Berdasarkan data dari gambar di atas, nilai rerata yang didapat siswa adalah 90 . Nilai 90 adalah nilai di atas KKM. Hanya 1 orang yang memperoleh nilai 70, nilai KKM di pelajaran ini. Jika dibandingkan dengan evaluasi di tengah semester, terdapat peningkatan nilai rata-rata yang diperoleh siswa. Meskipun demikian, belum bisa dipastikan jika hasil evaluasi ini terkait dengan penerapan flipped classroom. Karena melalui latihan di kelas menggunakan google meet dan google classroom, beberapa siswa masih kesulitan dalam berkomunikasi dengan bahasa Jepang sederhana.

Selain melalui evaluasi, peneliti juga melihat tanggapan siswa terhadap penerapan flipped classroom dalam pembelajaran bahasa Jepang. Tanggapan siswa diketahui melalui wawancara dan hasil angket pembelajaran. Dari 80 siswa kelas XII yang mengikuti pelajaran Bahasa Jepang, 54 siswa menanggapi melalui angket dan sisanya melalui wawancara. Hasil tanggapan siswa bisa dilihat pada diagram berikut. 
JPBJ, Vol. 7 No. 1, Februari 2021

ISSN: 2613-9618

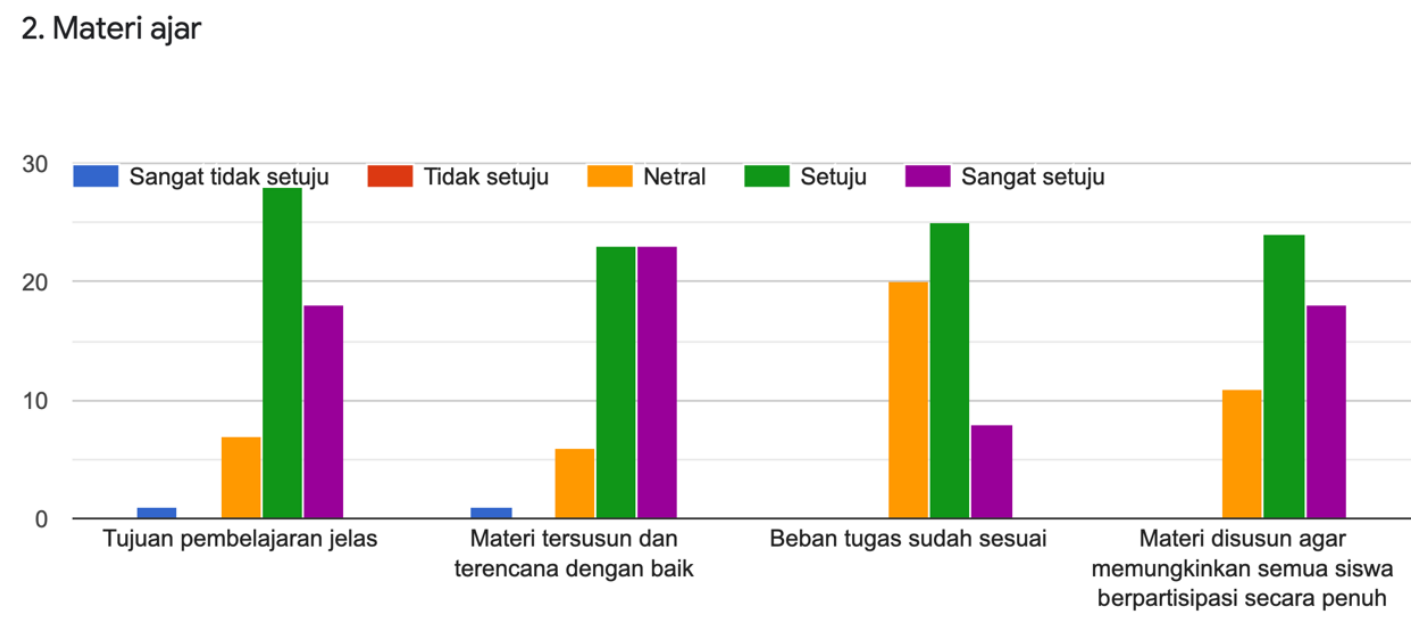

3. Apakah setelah belajar 1 semester ini anda memahami Bahasa Jepang walau sedikit?

54 tanggapan

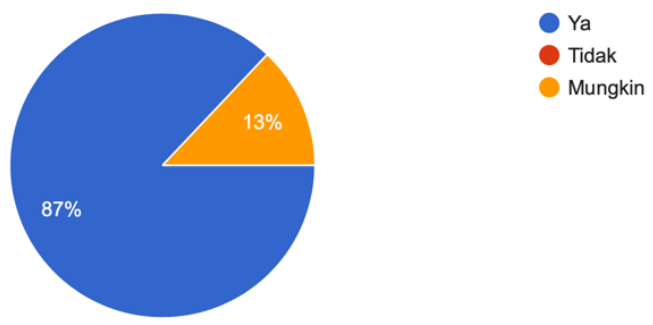

Diagram 1. Tanggapan siswa dalam angket

Pada pertanyaan tentang materi ajar, 24 dari 54 siswa setuju jika materi ajar memungkinkan siswa untuk berpartisipasi secara penuh. Sedangkan untuk pertanyaan tentang pemahaman bahasa Jepang, $87 \%$ siswa menjawab sudah memahami Bahasa Jepang walaupun sedikit. Dari hasil tanggapan siswa, bisa dikatakan bahwa, siswa merespon dengan baik penerapan flipped classroom dalam pembelajaran Bahasa Jepang.

\section{Simpulan dan Saran}

Meskipun mendapatkan tanggapan positif dari siswa, penerapan flipped classroom pada pembelajaran bahasa Jepang bisa berjalan baik karena penggunaan buku teks Marugoto. Buku teks Marugoto disusun secara tematik dan percakapan di dalamnya berdasarkan konteks. Ini memungkinkan guru menyusun tujuan pembelajaran mengikuti situasi dan lingkungan dari siswa.

Kelemahan dari penerapan flipped classroom pada pembelajaran bahasa Jepang adalah belum dilakukannya evaluasi yang terukur menyangkut efektivitas. Karena evaluasi yang dilakukan hanya pada pertengahan dan akhir semester melalui UTS dan PAS. Partisipasi siswa yang menonjol juga hanya tampak pada siswa yang benar-benar tertarik serius ingin mempelajari bahasa Jepang. Walaupun begitu, flipped classroom bisa menjadi salah satu solusi pembelajaran daring karena lebih membuat siswa berpartisipasi aktif dalam pembelajaran. Guru juga dituntut lebih kreatif dalam membuat video pembelajaran yang atraktif dan mengundang rasa ingin tahu siswa. Sebab, di era informasi teknologi sekarang, siswa mampu dengan mudah 
JPBJ, Vol. 7 No. 1, Februari 2021

ISSN: 2613-9618

mendapatkan materi di internet, sehingga guru harus bisa mencari bahan lain yang jarang atau tidak bisa didapatkan dari internet.

\section{Daftar Pustaka}

Bergman, Jonathan dan Aaron Sams. 2012. Flip Your Classroom: Reach Every Student in Every Class Everyday. Colorado: International Society for Technology in Education

Mok, Heng Ngee. (2014). Teaching Tip: The Flipped Classroom. Journal of Information System Education Vol. 25 No. 1 Spring 2014 HIm. 7-11.

https://ink.library.smu.edu.sg/sis_research

(diunduh pada tanggal 9 Januari 2021)

Sugiyono. 2016. Metode Penelitian Kuantitatif, Kualitatif dan R\&D. Bandung: Alfabeta

Tucker, Bill. (2012). The Flipped Classroom: Online instruction at home frees class time for learning. Education Next Vol. Winter 2012 HIm. 82-83.

http://www.msuedtechsandbox.com/MAETELy2-2015/wp-

content/uploads/2015/07/the_flipped_classroom_article_2.pdf

(diunduh pada tanggal 9 Januari 2021)

Wicaksono, Andri dan Ahmad Subhan Roza. 2016. Teori Pembelajaran Bahasa: Suatu Catatan Singkat. Yogyakarta: Garudawacha. 